\title{
The Postmodern Consumer: An Identity Constructor?
}

\author{
Manel Hamouda ${ }^{1} \&$ Abderrazak Gharbi ${ }^{1}$ \\ ${ }^{1}$ Faculty of Economic Sciences and Management, Tunis El Manar University, Tunis, Tunisia \\ Correspondence: Manel Hamouda, Faculty of Economic Sciences and Management, Tunis El Manar University, \\ PO Box 248, El Manar II 2092, Tunis, Tunisia. E-mail: manel.hamouda@gmail.com
}

$\begin{aligned} & \text { Received: December 13, } 2012 \\ & \text { Accepted: December 22, } 2012 \quad \text { Online Published: February 28, } 2013 \\ & \text { doi:10.5539/ijms.v5n2p41 }\end{aligned}$ URL: http://dx.doi.org/10.5539/ijms.v5n2p41

\begin{abstract}
This article attempts to contribute to better understand the postmodern consumer, by trying to identify one of its main characteristics: an identity constructor. Indeed, after studying the postmodern conditions, we have noticed that every condition favors the creation of identities voluntarily and consciously assumed by the consumer. The consumer is always looking to be socially desired by changing his identity every time he wishes. An empirical study was, therefore, conducted to confirm this postmodern consumer trend. The results found shows that the postmodern consumer is not seeking to manage his impression in front of others through changing identities but rather he seeks to live deeply himself in all identities which he built.
\end{abstract}

Keywords: postmodern conditions, consumer, identity construction, social desirability

\section{Introduction}

Postmodernism was a prominent social theory during almost three decades (Christensen \& al., 2005) but marketing field has not explicitly recognized postmodernism as an important descriptor of the current social condition than from the 90s (Lo 'pez-Bonilla \& Lo' pez-Bonilla, 2009). Postmodernism has to consider modalities through which individuals think and act as consumers in contemporary societies (Hirschman \& Holbrook, 1992; Holt, 1997; Thompson, 2002). Indeed, many researchers are attracted by postmodernism because of its interdisciplinary nature which allows the crossing of theoretical limits and gives a less limited and a richer vision of consumers (Miles, 1999). With the introduction of postmodernism as an analytical framework of contemporary consumer (Saren, 2011, Hirschman \& Holbrook, 1992; Firat \& Venkatesh, 1993), a new feature of the consumer was revealed as a constructor of identities voluntarily and consciously assumed by the consumer in order to live at best the various experiences of consumption (Firat, Sherry \& Vankatech, 1994). This phenomenon is called social desirability (Firat \& Shultz, 2001), the process by which people attempt to control the image that others have of them. The aim of research consists, therefore, in checking the psychological trait of "identity constructor" of the postmodern consumer. Thus, first, from a theoretical analysis of postmodern conditions, we will highlight the fact that each condition supports the process of creating identity by the postmodern consumer. The relationship between social desirability concept and identity construction will be identified in the following section. Finally, to check if postmodern consumer is an identity constructor we conducted an empirical study nearby 256 consumers whose results will be interpreted and discussed later.

\section{Postmodern Conditions and Consumer Identity Construction Process}

Firat and Vankatech (1993) identified five conditions of postmodernism: hyperreality, fragmentation, reversal of production and consumption, decentred subject, and paradoxical juxtaposition of opposites. Van Raaij (1993) adds to these conditions, pluralism and acceptance of differences as a dominant approach to all relationships. In 1997, Firat and Shultz, suggest other conditions of postmodern society such as: openness and tolerance, presenteeism, acceptance of disorder and chaos and importance of style and form. As suggested by Firat and Shultz (2001) and Brown (2006), the most common conditions used and which made a consensus on behalf of the authors and the researchers in postmodernism, are those advanced by Firat and Vankatech (1993), that regroup postmodern conditions into five categories. So, in the following sections, we will try to explain these conditions, and present their consequences on the consumer identity construction process.

\subsection{Hyperreality and Construction Identity}

In modern thought, the representation tries to understand the objective reality by means of observation and practice (Firat \& Vankatech, 1995). On the other hand, postmodernism rejects the myth of a universal and 
uniform reality to allow "re-creation" of new particular realities by releasing the sign of what it means and of its referent. In this perspective, the representation means the construction of reality without reference to the objective reality (Firat \& Vankatech, 1995): it is a hyperreal representation. Besides, the analysis of research conducted by Van Raaij (1993), Brown (1994) and Firat or Vankatech (1995) reveals that the hyperreality is a dimension systematically identified among the different dimensions of postmodernism. Hyperreality, is the condition of the constitution of social reality through powerful meanings, and thus, the consumer can build an identity. This process of identity construction plays an important role in the way of how the consumer perceives himself, how he identifies his purpose, his reason for being and to establish a meaningful sense to his life (Van Raaij, 1993; Firat \& al., 1995). The hyperreality which illustrates these facts is, mainly, found in communication forms. Indeed, through these communication forms, the signifiers can be detached from their original referents and meanings and become "floating". They can be attached to new meanings (Firat \& Vankatech, 1993). These new meanings simulated, leading to a new reality thanks to the communication power. It is a community of consumers who ascribe these new meanings of a brand (Van Raaij, 1993). As example that highlights these comments, we find the toothpaste case. In the commercial, the term is separated from the toothpaste and becomes independent of the original item (a paste used to clean teeth) and it will acquire new symbolic meanings, such as beauty, happiness, attractiveness. Consumers ascribe these new brand meanings (attractiveness, beauty,..) to their identities (Van Raaij, 1993). These new simulated meanings, led to a new reality thanks to the power of communication.

\subsection{Fragmentation and Construction Identity}

The fragmentation of life experiences often requires a fragmentation of the self in order to live deeply each situation encountered and may be even the possibility of the existence of incompatible or contradictory figures in the same individual. These are, identities voluntarily and consciously assumed by the consumer in order to immerse into consumption experiences, in so far as, that each one can construct and organize multiple individual identities (Davis, 2007). In each encountered situation there is the possibility of the existence of incompatible or contradictory personalities in the same individual, called the "multiphrenic selves". (Firat, Sherry \& Vankatech, 1994). "Multiphrenic self" is a representation of the effect of postmodern conditions on consumer behavior (Firat \& Shultz, 2001). This postmodern consumer trait shows that he accepts all the options and can be presented under different identities rather than to conform to a single one. Postmodern consumer is, then, a fragmented individual who lives fragmented and paradoxical consumption moments (Teschl, 2007). Postmodern individual is encouraged to change the image frequently and therefore, he trying to adapt himself to new roles and new identities (Decrop, 2008).

\subsection{Decentered Subject and Construction Identity}

The modernist "subject" has moved away from the centre and confused with the object. Postmodern discourse and culture, even, take away the human subject of its privileged status, there is rather recognition of the influence of objects to guide the desire of the individual (consumer) (Baudrillard, 1981). With the decentered subject condition, postmodernism highlights the confusion between subject and object in consumption and raises the question of control in their relationship. Specifically, the relationship between subject and object becomes more complicated, which makes redoubtable the assumed superiority of the subject.

The actions of each individual are determined by the design and structure of his products. We can, so, conclude that the role of the individual is to enable products to perform their functions and not products that enable the achievement of the individual goals. We are thus, reached the inverse of the vision supporting that products are designed to enable human being to achieve his goals. We observe this trend also in commercials as for Pepsi-Cola or Energizer batteries which have sometimes described the brand object as the hero while consumer, the human subject is at the margin, decentered, enjoying the show. Some authors, even, speak about "interpassivity "which is defined as the delegating of consumer's enjoyment to an object (Carù \& Cova, 2008). The postmodern subject is also decentered, as far as, he is no longer a single but a multiple subject changing according to the situation he encounters (Solomon, 1992). Indeed, multiplicity of images and personalities is not adopted by consumers in a deliberate way; it is rather imposed by cultural expectations that are already interiorized on society. People are always in quest to have the image that enables them to succeed. The role of self-construction as an object is related to some products (such as luxury goods or cars) or practices (Gomez \& Fosse-Ozcaglar, 2007), for example, many consumers (male and female) are using more and more plastic surgery and implants to grow more attractive a part or all their body.

\subsection{Reversal Production-Consumption and Construction Identity}

In postmodernity, there was a confusion or even a reversal of production and its destructive role of vested by 
economic theory. The consumer is, henceforth, considered as an actor and producer of meaning. Thanks to marketing system, consumption has become the process by which people define themselves, their statutes or images in contemporary society (Bourdieu, 1984; Ewen, 1988). Personal identity is increasingly looked for by the consumer, even in its fragmented forms, not on the basis of what we produce but on the basis of what we consume. The act of consumption is, indeed, in the heart of the process of identity construction. "To consume it is not only to buy products, but also, to buy an identity" (Gabriel \& Lang, 1995). As indicated by the postmodernists, consumption is not only a personal act of destruction, but also, a social act of symbolic meanings, social codes and relationships. In other words, each individual is different from another by a set of consumption choices and experiences. During consumption, the image belonging to a product or brand reflects an advantage for consumer. Product meaning is determined by the consumer, because the meaning is generated and interpreted by consumers themselves (Lee, 2009). So, during consumption, personal identity is created and recreated on the basis of use, rather than, on the basis of production or purchase. Consumption becomes more important. Many people identify themselves and communicate itself by their consumption activities, sports, recreation and musical preferences, rather than, their jobs (Vankatech \& Firat, 1995).

\subsection{Paradoxical Juxtaposition of Opposites and Identity Construction}

Since the confusion between subject and object is established (Firat \& Venkatech, 1995), they can be mutually represented and juxtaposed, resulting in a major feature of postmodern culture which is the paradoxical juxtaposition of opposites (Firat \& Vankatech, 1993). Everything can be combined and juxtaposed. Consensus between postmodern theorists that a key feature of postmodern culture is that its paradoxical trait that allows the juxtaposition of all. Theses contradictions may arise in the consumer, as opposed emotions (love and hatred, contempt and admiration), opposed cognitions (beliefs and doubt) that occur in individuals simultaneously (Foster, 1985; Hutcheon, 1988; Wilson, 1989).

Paradoxical juxtaposition can also refer to the existence of incompatible or contradictory personalities in the same individual, called the "multiphrenic selves." Firat, Sherry \& Vankatech (1994) (as we have seen in the fragmentation). Indeed, in the same individual we can identify contradictory and paradoxical behaviors (Elliot, 1997; Christopher, 1989).

\section{Postmodern Consumer and Social Desirability}

According to literature, postmodern conditions have a significant impact on the consumer, especially, at the level of his psychological characteristics. The construction of identities as diverse as contradictory (Van Raaij, 1993; Firat \& al., 1995; Firat \& Shultz, 2001; Davis, 2007; Decorp, 2008) to meet the different situation of postmodern individual is referred to an important consumer's psychological characteristic which is the social desirability. Firat and Shultz (2001) suggest that, the purpose of the postmodern consumer is to navigate multiple identities and personalities to fit all situations. There is even the possibility of the existence of incompatible or contradictory personalities in the same individual (Firat, Sherry \& Vankatech, 1994). In other words, consumers are always looking to be socially desired by changing their identity every time they wish: What will be defined as the level of social desirability (Firat \& Shultz, 2001). When people deliberately change their behavior and identity to match a given situation, this is called social desirability: a process by which people try to control the image which others have of them.

Individuals could seek to match their personal values with the acceptable social cultural factors (Fisher \& Katz, 2000; King \& Bruner, 2000). Many authors have also shown that the values are socially desirable constructs (Meglino \& Ravlin, 1998; Schwartz \& al., 1997). Social desirability is considered as a personality feature that characterizes orientations and positions of the individual toward social values (Edwards, 1957).

Paulhus (1984) revealed the existence of two different factors to describe social desirability concept: the self-deception and Impression management. Impression management refers to conscious strategies tailored to make a positive impression on others. Whereas, self-deception refers to unconscious and narcissistic self-promotion. In the latter case, an individual really believes his or her own exaggerations. Hence, individuals orient their answers to give itself (self deception) and / or to give to others (impression management) an image consistent with social norms (Paulhus, 1984). For Tournois \& al. (2000), impression management is a deliberate dupe to others, while the self-deception is unconscious dupe of itself, conceptualized by authors as a self defense mechanism or a self cognitive bias. We can therefore hypothesize that the postmodern orientations influence the social desirability of the consumer, more exactly his "self-deception" and his "impression management". To check this psychological trait of postmodern consumer, a quantitative study will be conducted and the methodology is exposed in the following paragraph. 


\section{Research Methodology}

The research methodology will be as follow: First, the presentation of the study sample. Second we expose the measurement scales that will help us to develop the questionnaire which is the tool of our investigation and finally the statistical treatment methods that will be adopted.

\subsection{Sample}

In our research we are interested in studying a psychological trait of postmodern consumer. Hence, our population is made up by all individuals of the society. For our study we chose the convenience method that allows on one hand, to facilitate the search of the interviewees and on the other hand, our goal is not to study individuals identified by name or to explain a subgroups behavior which supports the use of this type of sample (Calder \& al., 1981, Churchill \& Gilbert, 1995). So, due to the convenience method adopted, the questionnaire was distributed to all type of consumer. It was mainly focused on the friends, relatives, students and colleagues of the authors.

We cannot determine with precision the sample size given the non-probability sampling method adopted. Our goal is to interview the maximum of people depending on time available and interrogation conditions. So, 256 responses were collected. Among them, there are $51.2 \%$ men and $48.8 \%$ women. $66 \%$ of respondents have a university education level, $32.4 \%$ have a high school education and $1.6 \%$ for the primary school level.

\subsection{Measurement Scales}

To measure our study variables (postmodern orientations and social desirability), we used scales from the Anglo-Saxon literature. The use of existent scales is related to several advantages including objectivity, economy and generalization (Nunnally \& Bernstein, 1994).

Postmodern orientations measurement: Postmodern orientations reflect the holistic cultural sensibility of an individual (Lash, 1992; Lyotard, 1984), they are quite stable over time, as they reflect an overall approach of postmodern consumer regarding the meaning of life and existence (Firat \& Shultz, 2001). For example, postmodern consumer can navigate several identities and this sensitivity or overall orientation to life which enables this navigation and this multiplicity. These orientations extracted from postmodern conditions are composed by three dimensions: multiphrenic self, decentered subject and hyperreality (Firat \& Shultz, 2001). To measure the postmodern orientations we used Firat and Shultz scale which is to our knowledge, the only scale developed to this day. So, the scale is composed by three dimensions which reflect the construct nature:

- Multiphrenic self dimension: it's the result of both postmodern conditions: fragmentation and the paradoxical juxtaposition of opposites. Multiphrenic self implies that postmodern individual tend to be present under different identities rather than conforming to a single one.

- Decentered subject dimension: which reflects the influence of objects to guide individual (consumer) desires (Baudrillard, 1981; Faoucault, 1970). The postmodern consumer seems to have a greater acceptance and comfort with the decentered existence.

- Hyperreality dimension: it is related to the hyperreality condition, considered as the constitution of social reality through powerful meanings and representations of simulation (Firat \& Venkatech, 1993).

Postmodern orientations scale is composed by 12 Likert items with items answered on a five point scale from "strongly disagree" to "strongly agree".

Social desirability measurement: To measure social desirability we used the BIDR (Balanced Inventory of Desirable Responding) scale developed in 1984 by Paulhus. This instrument measures two dimensions of social desirability:

- Self deception: defined as an unconscious dupe of itself.

-Impression management: defined as a deliberate dupe to others.

Each dimension is composed by 20 items. Items are Likert-type answered on a five point scale from "strongly disagree" to "strongly agree".

\subsection{Statistical Treatment Methods}

At First, we try to improve the reliability and validity of the used measurement scales through an exploratory factor analysis. The exploratory factor analysis is used to check measurement scale dimensionality and the construct reliability. Dimensionality will be validated using the Bartlett's test of sphericity which must be significant (associated probability is less than 0.05) and Kaiser, Meyer and Olkin (KMO) Index acceptable from a value of 0 7. Concerning the number of factors retained, it is determined by the cumulative percentage of 
variance extracted. In social sciences, it is recommended that the factors extracted should account for at least $60 \%$ of the variance (Malhotra, 1993). For the reliability analysis, we will calculate the coefficient of reliability Cronbach's alpha for each dimension. This coefficient has been proposed to detect items that affect the quality of the construct (Churchill \& Peter, 1984). Cronbach's alpha attempts to estimate the internal consistency between items. If this index is close to 1 (and greater than 0.7), we consider that the variables related to this component measure the same construct (internal consistency) (Evrard \& al., 2003). In a second step, we subjected each scale to a confirmatory factor analysis. The tested structure is the one stemming from the exploratory factorial analysis The objective is to confirm the factor structure of the scale by taking into account the error terms as far as the consideration of the error terms provides a better accurate results (Mackenzie, 2001). To check the relationship between social desirability and postmodern orientations we chose the multiple linear regression that explains a dependent variable (interval or ratio scale) by one or more independent variables (interval or ratio scale) (Evrard $\&$ al., 2003) . Indeed, in our research, we try to explain a dependent variable (social desirability) by several independent variables (multiphrenic self, decentered subject and hyperreality). All Our variables are interval scale type. Thus, the conditions of application of the regression are checked.

\section{Results}

We present first the results of measurement scales validity, through the exploratory and confirmatory factor analysis. Then we proceed to the statistical test results obtained thanks to the multiple linear regression.

\subsection{Measurement Scales Validity}

Overall, the constructs of our study have a good internal consistency. The results of the exploratory factor analysis of the measurement scales are presented, in the Table1. Whereas, Table 2 displays confirmatory factor analysis results.

Table 1. Exploratory factor analysis of the measurement scales

\begin{tabular}{|c|c|c|c|c|c|}
\hline & \multicolumn{3}{|c|}{ Postmodern orientations } & \multicolumn{2}{|c|}{ Social Desirability } \\
\hline Dimension & Multiphrenic self & $\begin{array}{l}\text { Decentered } \\
\text { Subject }\end{array}$ & Hyperrealiy & Self Deception & $\begin{array}{l}\text { Impression } \\
\text { Management }\end{array}$ \\
\hline $\begin{array}{l}\text { Cronbach's } \\
\text { alpha }\end{array}$ & 0.922 & 0.973 & 0.962 & 0.92 & 0.894 \\
\hline $\begin{array}{l}\% \quad \text { variance } \\
\text { Explained }\end{array}$ & \multicolumn{3}{|l|}{88.100} & \multicolumn{2}{|l|}{92.362} \\
\hline $\begin{array}{l}\text { KMO and } \\
\text { Bartlett's test }\end{array}$ & \multicolumn{3}{|c|}{$\begin{array}{l}\mathrm{KMO}=0.849 ; \\
\text { Approx. Chi-Square }=2983.157 ; \mathrm{df}=66 ; \text { Sig. }= \\
0.000\end{array}$} & \multicolumn{2}{|c|}{$\begin{array}{l}\mathrm{KMO}=0.967 ; \\
\text { Approx. Chi-Square }=22279.307 ; \mathrm{df} \\
=780 ; \text { Sig. }=0.000\end{array}$} \\
\hline
\end{tabular}

Table 2. Confirmatory factor analysis results of the measurement scales

\begin{tabular}{lll}
\hline & Postmodern orientations & Social Desirability \\
\hline$\chi 2$ & 3.125 & 1.680 \\
Df & 40 & 659 \\
CFI & 0.970 & 0.979 \\
TLI & 0.958 & 0.978 \\
RMSEA & 0.091 & 0.052 \\
P & 0.000 & 0.000 \\
\hline
\end{tabular}

\subsection{Postmodern Orientations Effects on Consumer Social Desirability}

To test the relationship between postmodern orientations and consumer social desirability required checking the relationship between the three dimensions of postmodern orientations (multiphrenic self, decentered subject and hyperreality) with each component of social desirability: self-deception and impression management, using multiple linear regression. The results obtained are summarized in Table 3. 
Table 3. Postmodern orientations effects on consumer's social desirability

\begin{tabular}{|c|c|c|c|c|c|c|c|c|c|c|}
\hline \multirow[t]{3}{*}{ Independent Variables } & \multicolumn{10}{|c|}{ Dependent Variable } \\
\hline & \multicolumn{5}{|c|}{ Self Deception } & \multicolumn{5}{|c|}{ Impression Management } \\
\hline & Beta & $\mathbf{t}$ & Sig & Tol & VIF & Beta & $\mathrm{t}$ & Sig & Tol & VIF \\
\hline Decentered subject & 0.098 & 1.490 & 0.138 & 0.900 & 1.111 & -0.185 & -2.886 & 0.004 & 0.900 & 1.111 \\
\hline Multiphrenic self & 0.031 & 0.466 & 0.641 & 0.909 & 1.101 & -0.145 & -2.276 & 0.024 & 0.909 & 1.101 \\
\hline Hyperreality & 0.044 & 0.676 & 0.500 & 0.912 & 1.097 & -0.008 & -0.125 & 0,901 & 0,912 & 1,097 \\
\hline \multirow[t]{4}{*}{ (constant) } & $1.195 \mathrm{E}-16$ & 0.000 & 1.000 & & & 0.003 & 0.045 & 0.964 & & \\
\hline & \multicolumn{5}{|c|}{ Durbin-Watson $=2.029$} & \multicolumn{5}{|c|}{ Durbin-Watson= 2.156} \\
\hline & $\mathbf{F}=1.430$ & $\mathbf{P}=0$ & & & & $\mathbf{F}=6.3$ & & $=0.000$ & & \\
\hline & \multicolumn{5}{|c|}{ Adjusted R-square $=0.005$} & \multicolumn{5}{|c|}{ Adjusted R-square $=0.059$} \\
\hline
\end{tabular}

- Self-Deception: The results of multiple regressions analyzing the impact of postmodern orientations respect the conditions of application of the method: linearity between dependent and independent variables as well as homoscedasticity are examined through the scatterplot, the absence of autocorrelation with Durbin Watson test and the absence of strong multicollinearity by checking the Variance Inflation Factor (VIF) and the Tolerance (Tol). According to the table, we note that the Fisher test is not significant $(p=0.234)$ so the model is not significant. The model has accounted for $0.5 \%$ of self-deception variance. But no factor contributes significantly to explain consumer self-deception.

- Impression Management: The two conditions linearity and homoscedasticity are checked by examining the scatterplot. Also, Durbin Watson test indicated a value of 2.156, below the acceptable threshold of 2.5, hence, the condition of absence of autocorrelation is respected. Finally, the values of the inflation factor (VIF) and Tolerance (Tol) are satisfactory for all independent variables (respectively lower than 4 and greater than 0.3).

Regression only extracts a single significant model $(\mathrm{p}=0.004)$. This model has an adjusted-R square equal to 0.059 which explains $5.9 \%$ of consumers' impression management variance. This variance is accounted by two significant variables: the decentered subject $(p=0.004)$ and the multiphrenic self $(p=0.024)$. The decentered subject and the multiphrenic self have a negative effect on consumer impression management: Standardized beta coefficient associated with each variable is negative, -0.185 for the decentered subject and -0.145 for the multiphrenic self. Hyperreality does not have a significant effect on impression management.

\section{Discussion}

By referring to our results, we found that no postmodern orientation has an influence on self deception dimension of social desirability. However, the results show that two postmodern orientations: the decentered subject and the multiphrenic self, have an impact on the impression management or the control of the social self-image, indicating the trend to present a favorable self image to others (Tourois \& al., 1997; 2000). First, the decentered subject influences the impression management, indeed, according to some authors (Gergen, 1991; Solomon, 1992) the subject is decentered as far as it is no longer unique and single subject but multiple subject changing within the situation he encounters. Also, the multiplicity of identity is one of the most important consequences of the decentered subject condition (Firat \& Dholakia, 2006). Thus the relationship between decentered subject and impression management seems to be justified. Then for the "multiphrenic self", this postmodern orientation which is a combination of two conditions: fragmentation and paradoxical juxtaposition of opposites (Firat \& Shultz, 2001), has an effect on impression management dimension of social desirability. This relationship shows that a postmodern individual (postmodern consumer) accepts all the possibilities and can be present under different identities rather than conforming to a single one, in order to give a favorable image to others. This result therefore supports the idea that the postmodern consumer is a fragmented individual, who is living fragmented, and paradoxical moments and experiences of consumption. Thus, as suggested by literature, postmodern consumers feel more comfortable with the different personalities they adopt. An interpretation could be made that consumers like managing the impressions, in different situations in which they are called to present different self images. Nevertheless, our analysis gives an opposite result in terms of this relationship sense: greater the postmodern orientations (decentered subjects and multiphrenic self), less is the score on impression management scale.

The interpretation which may explain this result is that when postmodern consumers adopt different identities, they immerse themselves in each experience to become this identity in order to live it fully and deeply (Firat \& Shultz, 2001). For postmodern consumers, it is not a question of managing an impression in front of others, but in fact they become the one whom they represent in each experience. Each identity is a real experience, not a 
means to manage impressions. This is an additional proof that postmodern consumers are more comfortable to use and live in and with different principles. The construction of multiple identities is not just a simple mean of impression management with the trend of «individual objectification» (Fosse-Gomez \& Ozcaglar, 2007): a postmodern manifestation of individual who seeks the multiplicity of images and personalities. People always tend to have the image that corresponds to that required and requested by others to succeed. The increasing use of plastic surgery is a concrete example of the objectification which makes the individual and allows him to be bought and consumed, similarly as a product. Consumers become products consumed by others, and they are ready even to change their bodies to conform with the identity that they adopt which exceeds a simple impression management.

\section{Conclusion}

According to literature, postmodern conditions have a significant incidence on the consumer, especially in terms of psychological characteristics such as the construction of identities so diverse as contradictory (Van Raaij, 1993; Firat \& al., 1995; Firat \& Shultz, 2001; Davis, 2007; Decrop, 2008) to meet the different situations in which the postmodern individual is. The postmodern consumer is not seeking to manage his impression in front of the others but rather to live deeply himself in all the identities which he used as we found in our result that the multiphrenic self dimension of the postmodern orientations is the only dimension that influence negatively the impression management component of social desirability. "Marketing" has to challenge its conceptions and definitions of the consumer and consumption. Marketing must be redefined as a generator for consumers, rather than a final products supplier (Firat \& al., 1995). It could then be admitted according to Firat and Dholakia (2006) that no product offered to consumers is never a finished product and the consumption was always a process of transformation of the product from the moment when the product is in possession of consumers.

It is a consumer integrated marketing, an activity that everyone does, such as the results found that consumers become the products consumed by others, and are willing to change their body to well convey their image. Each consumer has its own marketing: Managers should expect to a "deprofessionalization" of marketing for the benefit of consumers in the way that each one becomes a professional and an expert in marketing know-how. Integrated marketing seems to become the domain of each one, a process by which the postmodern individuals imagines, built their identities, in order to live a significant and deep experience of each moment of his life (Firat \& Dholakia, 2006).

\section{References}

Baudrillard, J. (1981). For a Critique of the Political Economy of the Sign. St. Louis: Telos.

Bourdieu, P. (1984). Distinction: A social critique of the judgement of taste. Cambridge, MA: Harvard University Press.

Brown, S. (1994). Marketing as Multiplex: Screening Postmodernism. European Journal of Marketing, 28, 27-51. http://dx.doi.org/10.1108/03090569410067631

Brown, S. (2006). Recycling Postmodern Marketing. The Marketing Review, 6, 211-230. http://dx.doi.org/10.1362/146934706778605322

Calder, B. J., Phillips, L. W. \& Tybout, A. M. (1981). Designing research for application. Journal of Consumer Research, 8, 197-207.

Carù, A., \& Cova, B. (2008). Le consommateur interpassif: nouvel avatar postmoderne? 7ème Congrès des Tendances du Marketing. Venise.

Christensen, L. T., Tord, S., \& Firat, A. F. (2005). Integrated marketing communication and postmodernity: An odd couple?. Corporate Communications, 10, 156-167. http://dx.doi.org/10.1108/13563280510596961

Christopher, M. (1989). The existential consumer. European Journal of Marketing, 23, 80-84. http://dx.doi.org/10.1108/EUM0000000000585

Churchill, G. A., \& Peter, J. P. (1984). Research design effects on the reliability of rating scales: a meta-analysis. Journal of Marketing Research, November, 26-41.

Churchill, J., \& Gilbert, A. (1995). Marketing Research: methodological foundations. The Dryden Press.

Davis, J. B. (2007). Postmodernism and the Individual as a Process. Review of Social Economy, 2, 203-208. http://dx.doi.org/10.1080/00346760701345581

Decrop, A. (2008). Les paradoxes du consommateur postmoderne. Reflets et perspectives de la vie économique, 2, 85-93. 
Edwards, A. L. (1957). Social desirability variable in personality assessment and research. New York: Holt, Rinehart \& Winston.

Elliot, R. (1997). Existential consumption and irrationnal desire. European Journal of Marketing, 31, 285-296. http://dx.doi.org/10.1108/03090569710162371

Evrard, Y., Pras, B., \& Roux. E. (2003). Market: Etudes et Recherche en Marketing. Paris: Dunod.

Ewen, S. (1988). All consuming images: The politics of style in contemporary culture. New York, NY: Basic Books.

Firat, A. F. (1992). Fragmentations in the postmodern. Advances in Consumer Research, 19, 203-206.

Firat, A. F., \& Dholakia, N. (2006). Theoretical and philosophical implications of postmodern debates some

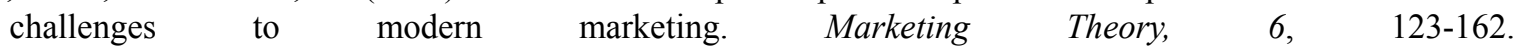
http://dx.doi.org/10.1177/1470593106063981

Firat, A. F., \& Shultz, C. J. (2001). Preliminary metric investigation into the nature of the postmodern consumer. Marketing Letters, 12, 189-203. http://dx.doi.org/10.1023/A:1011173205199

Firat, A. F., \& Venkatesh, A. (1993). Postmodernity: The Age of Marketing. Intenational Journal of Research in Marketing, 10, 227-249. http://dx.doi.org/10.1016/0167-8116(93)90009-N

Firat, A. F., \& Venkatesh, A. (1995). Liberatory Postmodernism and the Reenchantment of Consumption. Journal of Consumer Research, 22, 239-267.

Firat, A. F., Sherry, J. F., \& Venkatesh, A. (1994). Postmodernism, marketing and the consumer. International Journal of Research in Marketing, 11, 311-316.

Firat, A., \& Shultz, C. J. (1997). From segmentation to fragmentation: markets and marketing strategy in the postmodern era. European Journal of Marketing, 31, 183-207. http://dx.doi.org/10.1108/EUM0000000004321

Firat, A.F., Dholakia, N., \& Venkatesh, A. (1995). Marketing in postmodern world. European Journal of Marketing, 29, 40-56. http://dx.doi.org/10.1108/03090569510075334

Fisher, R. J., \& Katz, J. E. (2000). Social-desirability bias and the validity of self-reported values. Psychology and Marketing, 17, 105-120. http://dx.doi.org/10.1002/(SICI)1520-6793(200002)17:2<105::AID-MAR3>3.0.CO;2-9

Fosse-Gomez, M. H., \& Ozcaglar, N. (2007). Towards an understanding of consumption objectors. European Advances in Consumer Research, 8, 493-497.

Foster, H. (1985). Recodings: Art, Spectacle, Cultural Politics. Seattle, WA: Bay Press.

Gabriel, Y., \& Lang, T. (1995). The unmanageable consumer. Contemporary consumption and its fragmentation. London: Sage.

Gergen, K. (1991). The saturated self: Dilemmas of identity in contemporary life. New York: Basic Books.

Hirschman, E. C., \& Holbrook, M. B. (1992). Postmodern consumer research. Newbury Park: Sage Publications.

Holt, D. B. (1997). Poststructuralist Lifestyle Analysis: Conceptualizing the Social Patterning of Consumption in Postmodernity. Journal of Consumer Research, 23, 326- 349. http://dx.doi.org/10.1086/209487

Hutcheon, L. (1988). A Poetics of Postmodernism: History, Theory, Fiction. New York: Routledge.

King, M. F., \& Bruner, G. C. (2000). Social desirability bias: A neglected aspect of validity testing. Psychology $\begin{array}{lll}\text { and } \quad \text { Marketing, 79-103. } & \text { 17, }\end{array}$ http://dx.doi.org/10.1002/(SICI)1520-6793(200002)17:2<9::AID-MAR2>3.0.CO;2-0

Lash, S. (1992). Sociology of Postmodernism. London: Routledge.

Lee, E. J. (2009). Theoretical foundation of brand personality for postmodern branding dynamics: a critical review and research agenda. Advances in Consumer Research, 36, 886-887.

Lo' pez-bonilla, L. M., \& Lo' pez-bonilla, J. M. (2009). Postmodernism and Heterogeneity of Leisure Tourist Behavior Patterns. Leisure Sciences, 31, 68-83. http://dx.doi.org/10.1080/01490400802558210

Lyotard, J. (1984). The postmodern condition: A report on knowledge. Minneapolis: University of Minnesota Press. 
MacKenzie, S. B. (2001). Opportunities for improving consumer research through latent variable structural equation modeling. Journal of Consumer Research, 28, 159-166.

Malhotra, N. (1993). Marketing research: An applied orientation. Prentice-Hall: New Jersey.

Meglino, B. M., \& Ravlin, E. C. (1998). Individual values in organizations: Concepts, controversies and research. Journal of Management, 24, 351-389. http://dx.doi.org/10.1177/014920639802400304

Miles, S. (1999). A pluralistic seduction: Postmodernism at the crossroads. Consumption, Culture and Markets, 3, 145-163.

Nunnally, J. C., \& Bernstein, I. H. (1994). Psychometric theory (3rd ed.). New York: McGraw- Hill.

Paulhus, D. L. (1984). Two-component models of socially desirable responding. Journal of Personality and Social Psychology, 46, 598-609. http://dx.doi.org/10.1037/0022-3514.46.3.598

Poster, M. (1975). Translator's Introduction. In Jean Baudrillard (Ed.), The Mirror of Production. St. Louis: Telos.

Saren, M. (2011). Marketing empowerment and exclusion in the information age. Marketing Intelligence \& Planning, 29, 39-48. http://dx.doi.org/10.1108/02634501111102733

Schwartz, S. H., Verkasalo, M., Antonovsky, A., \& Sagiv, L. (1997). Value Priorities and Social Desirability: Much Substance, Some Style. British Journal of Social Psychology, 36, 3-18. http://dx.doi.org/10.1111/j.2044-8309.1997.tb01115.x

Solomon, M. R. (1992). Consumer Behavior: Buying, Having, and Being. Boston, MA: Allyn \& Bacon.

Teschl, M. (2007). What Does it Mean to be Decentered? Review of Social Economy, 2, 195-201. http://dx.doi.org/ 10.1080/00346760701345532

Thompson, C. J. (2002). A Re-Inquiry on Re-Inquiries: A Postmodern Proposal for a Critical-Reflexive Approach. Journal of Consumer Research, 29, 142-145.

Tournois, J., Mesnil, F., \& Kop, J. L. (2000). Autotricherie et hétérotricherie : Un instrument de mesure de la désirabilité sociale. Revue Européenne de Psychologie Appliquée, 50, 219-232.

Van Raaij, W. F. (1993). Postmodern consumption. Journal of Economic Psychology, 14, 541-563. http://dx.doi.org/10.1016/0167-4870(93)90032-G

Wilson, E. (1989). Hallucinations: Life in the Post-Modern City. London: Hutchinson Radius. 